\title{
Bioavailability of diphenylhydantoin
}

A four-way crossover study was performed in 8 adult volunteers using a Latin square design with 4 groups of 2 subjects arranged in order of increasing body weight. Single $100 \mathrm{mg}$ doses of diphenylhydantoin (DPH) sodium were administered as an aqueous solution (treatment A), the innovator's capsule (treatment B), and a commercially available generic capsule (treatment D). A single $300 \mathrm{mg}$ dose (treatment $\mathrm{C}$ ) was also administered as three $100 \mathrm{mg}$ (innovator's) capsules. DPH capsules from both manufacturers gave plasma levels that were not significantly different at any sampling time. Although DPH following treatment A was absorbed more rapidly, producing higher initial plasma levels than treatments $B$ and $D$, the areas under the curves for the three treatments were equivalent. The area under the curve for treatment $C$ was also three times that for treatment B. Plasma DPH concentrations were related to the reciprocal of body weight, but plasma protein binding had no effect on the observed intersubject variance in plasma levels.

Kenneth S. Albert, Ph.D., Ermelinda Sakmar, B.S., Margarette R. Hallmark, M.A., Donald J. Weidler, M.D., Ph.D., and John G. Wagner, Ph.D. Ann Arbor, Mich. College of Pharmacy and Upjohn Center for Clinical Pharmacology, The University of Michigan

Diphenylhydantoin (DPH) is an anticonvulsant widely used in the prophylactic management of grand mal and psychomotor seizures. ${ }^{4}$ Although DPH plasma levels have been correlated with dose, toxicity, and seizure control, ${ }^{16}$ the situation is complicated by dose-dependent kinetics. ${ }^{1,6,9}$ In addition, the physicochemical factors that influence the bioavailability

\footnotetext{
The study was performed pursuant to Contract No. FDA 69-22 with the Public Health Service, Food and Drug Administration, Department of Health, Education, and Welfare, and was supported in part by Public Health Service Grant No. 5-PI1-GM15559.

Received for publication May 7, 1974.

Accepted for publication June 13, 1974.

Reprint requests to: Dr. John G. Wagner, Upjohn Center for Clinical Pharmacology, The University of Michigan.
}

of DPH can dramatically affect both the rate and extent of its absorption. ${ }^{7,} 10$ In this context, significant differences in plasma drug levels were observed by Martin and associates ${ }^{13}$ and Arnold and associates ${ }^{2}$ following single doses of DPH obtained from different manufacturers.

The present study was undertaken: (1) to compare plasma levels of DPH after oral administration of single $100 \mathrm{mg}$ doses of diphenylhydantoin sodium as an aqueous solution, the innovator's capsule, and a commercially available generic capsule; and (2) to determine whether the dose dependency exhibited by DPH influences its bioavailability in the therapeutic range of 100 to $300 \mathrm{mg}$. 
Table I. Dosage schedule and treatments

\begin{tabular}{c|c|c|c|c|c}
\hline & & \multicolumn{4}{|c}{ Treatment } \\
\cline { 3 - 6 } $\begin{array}{c}\text { Sub- } \\
\text { jects }\end{array}$ & Group & $\begin{array}{c}\text { Phase } \\
I\end{array}$ & $\begin{array}{c}\text { Phase } \\
I I\end{array}$ & Phase & Phase \\
\hline 1,2 & I & $\mathrm{A}^{*}$ & $\mathrm{~B} \dagger$ & $\mathrm{D} \ddagger$ & $\mathrm{C} \$$ \\
3,4 & II & B & C & A & D \\
5,6 & III & C & D & B & A \\
7,8 & IV & D & A & C & B \\
\hline
\end{tabular}

Oral solution ( $100 \mathrm{mg}$ ): The contents of one Dilantin Kapseal, $100 \mathrm{mg}$ (Parke, Davis \& Co.), dissolved in a mixture composed of $10 \mathrm{ml}$ of $95 \%$ ethanol, $35 \mathrm{ml}$ of propylene glycol, $40 \mathrm{ml}$ of $\mathrm{pH} 6.8$ phosphate buffer (1 M in total phosphate), and $40 \mathrm{ml}$ of Coca-Cola syrup, were swallowed; the container was rinsed with $120 \mathrm{ml}$ of water and the rinsings were swallowed.

†Innovator's capsule (100 mg): One Dilantin Kapseal, $100 \mathrm{mg}$, was swallowed intact with $240 \mathrm{ml}$ of water.

†Generic capsule $(100 \mathrm{mg})$ : One diphenylhydantoin sodium capsule, $100 \mathrm{mg}$ (distributed by Pharmacon Inc., Detroit) was swallowed intact with $240 \mathrm{ml}$ of water.

\$Innovator's capsule $(300 \mathrm{mg})$ : Three Dilantin Kapseals, $100 \mathrm{mg}$ each, were swallowed intact with $240 \mathrm{ml}$ of water.

\section{Methods}

Protocol. Eight healthy adult male volunteers between the ages of 21 and 40 and weighing between 70 and $95 \mathrm{~kg}$, with normal vital signs and laboratory screening values, were selected. The study was performed using a Latin square design with 4 groups of 2 subjects, arranged in order of increasing body weight. Each subject received 3 single $100 \mathrm{mg}$ doses and one single $300 \mathrm{mg}$ dose of diphenylhydantoin sodium orally, 2 weeks apart according to the dosage schedule shown in Table I. The subjects fasted from 10 hours prior to dosing until 4 hours post administration of the drug.

Ten-milliliter blood samples were collected in heparinized Vacutainers just prior to dosing and at $0.5,1,2,4,6,8,12,24$, 48,72 , and 96 hours after dosing. The plasma was separated, frozen, and kept in a frozen state until just prior to assay.

Analytical method. Two-milliliter plasma samples were assayed for unchanged DPH by the benzophenone procedure described by Dill and associates ${ }^{3}$ using the following modifications suggested by Saitoh and associates $^{14}$ : (1) benzophenone was formed by oxidizing DPH with alkaline permanganate for 10 minutes at $80^{\circ}$; (2) benzophenone, which was extracted into $2.0 \mathrm{ml}$ of spectrophotometric grade n-heptane (Matheson, Coleman, and Bell, Norwood), was measured at $247 \mathrm{~nm}$ in $10 \mathrm{~mm}$ microcells using an approximately expanded scale ( 0 to 0.1 or 0 to 0.5 absorbance units full-scale deflection) of a spectrophotometer (Gilford Model 2400 spectrophotometer, Gilford Instrument Laboratories, Inc., Oberlin).

Plasma protein binding. One-milliliter portions of drug-free plasma and plasma samples from treatment C (see Table VI) for each subject were incubated for 30 minutes at $25^{\circ} \mathrm{C}$ with $10 \mu \mathrm{l}$ of ${ }^{14} \mathrm{C}$-labeled DPH (New England Nuclear Corp., Boston; specific activity, $5.21 \mathrm{mCi} / \mathrm{mM}$ ) using a methanolic stock solution, $4.88 \mu \mathrm{g} / \mathrm{ml}$.

Ultrafiltration of the plasma samples was performed at $25^{\circ} \mathrm{C}$ in membrane cones (centriflo CF-50 membrane ultrafilter; Amicon Corp., Lexington), which were soaked in deionized water at least 1 hour before use. After removing residual water by centrifuging at $1,000 \mathrm{~g}$ for 5 minutes 0.9 $\mathrm{ml}$ of plasma was pipetted into the cone and then centrifuged at $800 \mathrm{~g}$ for $30 \mathrm{~min}$ utes. At the end of the centrifugation, 100 $\mu \mathrm{l}$ aliquots of ultrafiltrate were removed for scintillation counting (Packard TriCarb Liquid Scintillation Spectrometer, Packard Instrument Co., Inc., Downers Grove) in vials containing $15 \mathrm{ml}$ of Unogel (Schwarz/Mann Co., Orangeburg). A 100 $\mu \mathrm{l}$ portion of plasma was also analyzed for radioactivity prior to centrifugation. The fraction unbound was calculated as the quotient of the radioactivity in the ultrafiltrate and in the plasma before ultrafiltration.

Statistical analysis. Plasma concentrations at each sampling time, peak plasma concentrations and times of their occurrence, and areas were analyzed by analysis of variance for crossover design. The sources of variation in this type of analysis are groups, subjects within a group, time periods, treatments, and residual. 

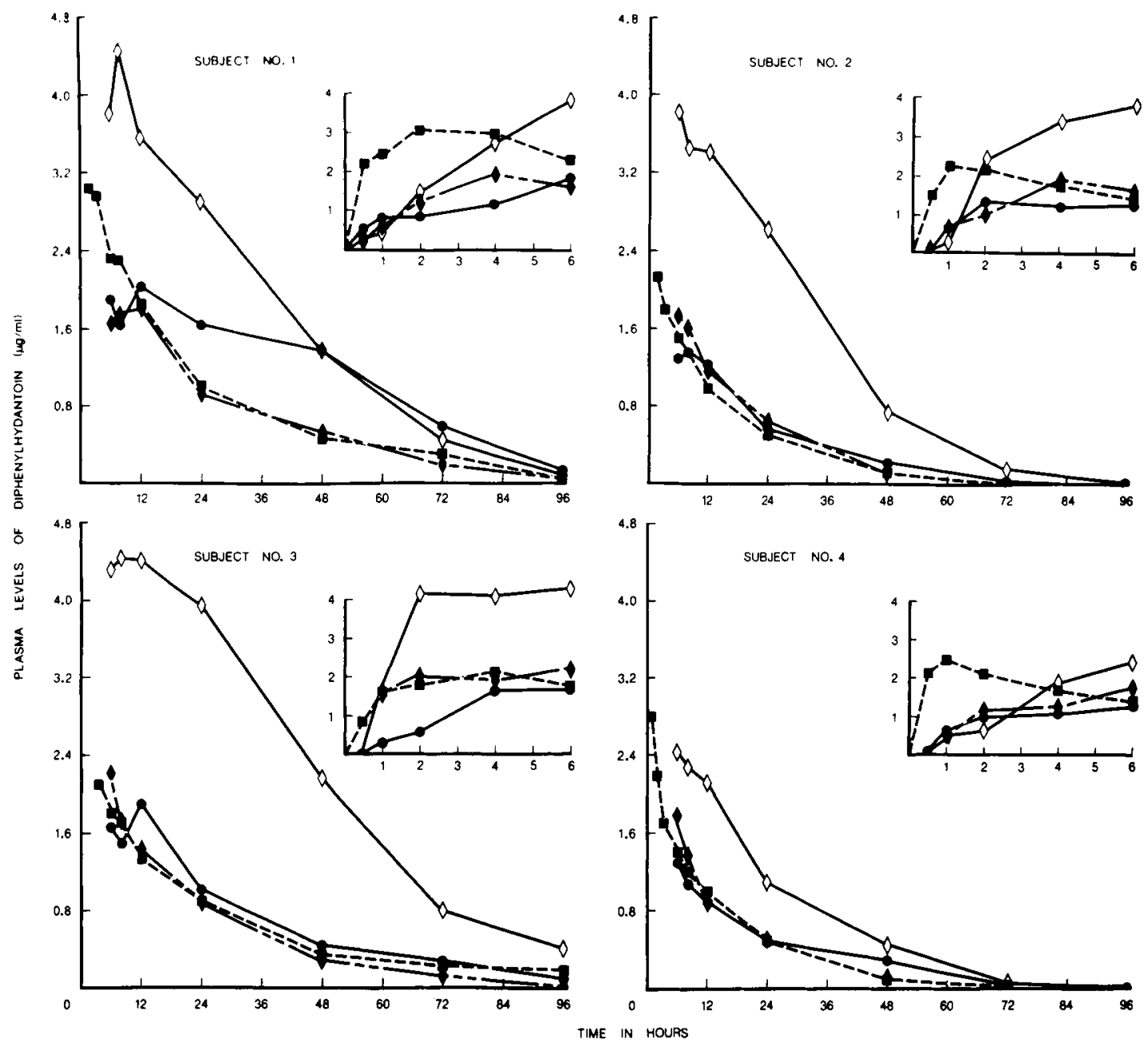

Fig. 1, DPH plasma concentration, time data in Subjects 1 to 4 following 4 oral treatments: treatment A from time of peak to $96 \mathrm{hr}$; treatments $\mathrm{B}, \mathrm{C}$, and D from $6 \mathrm{hr}$ to $96 \mathrm{hr}$. Inserts

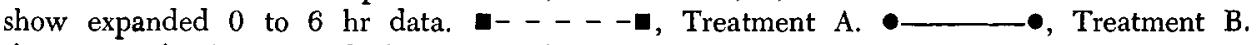
$\diamond \longrightarrow$, Treatment C. $\diamond-\cdots$, , Treatment D.

\section{Results}

Comparison of treatments. Figs. 1 and 2 graphically depict DPH plasma concentration, time data in 8 subjects following the 4 oral treatments, while Table II and Fig. 3 summarize the averages at each of 11 sampling times post administration of the drug. The analysis of variance and multiple-range tests for comparing averages of pairs of treatments ${ }^{\bar{n}}, 15$ are presented in Table III. The pharmacokinetic parameters derived from the plasma level data appear in Table IV, while Table $V$ reports the corresponding statistical analyses.
Analysis of variance for crossover design indicated that the differences among treatment averages were highly significant at all sampling times except 96 hours (Tables II and III). Differences among treatment average peak plasma concentrations of $\mathrm{DPH}$, the times of their occurrence, and treatment average areas under the plasma curves were also highly significant (Tables IV and V).

Multiple-range tests indicated that average plasma concentrations of DPH following treatments $\mathrm{A}$ and $\mathrm{B}$ differed significantly at $0.5,1,2$, and 4 hours post- 

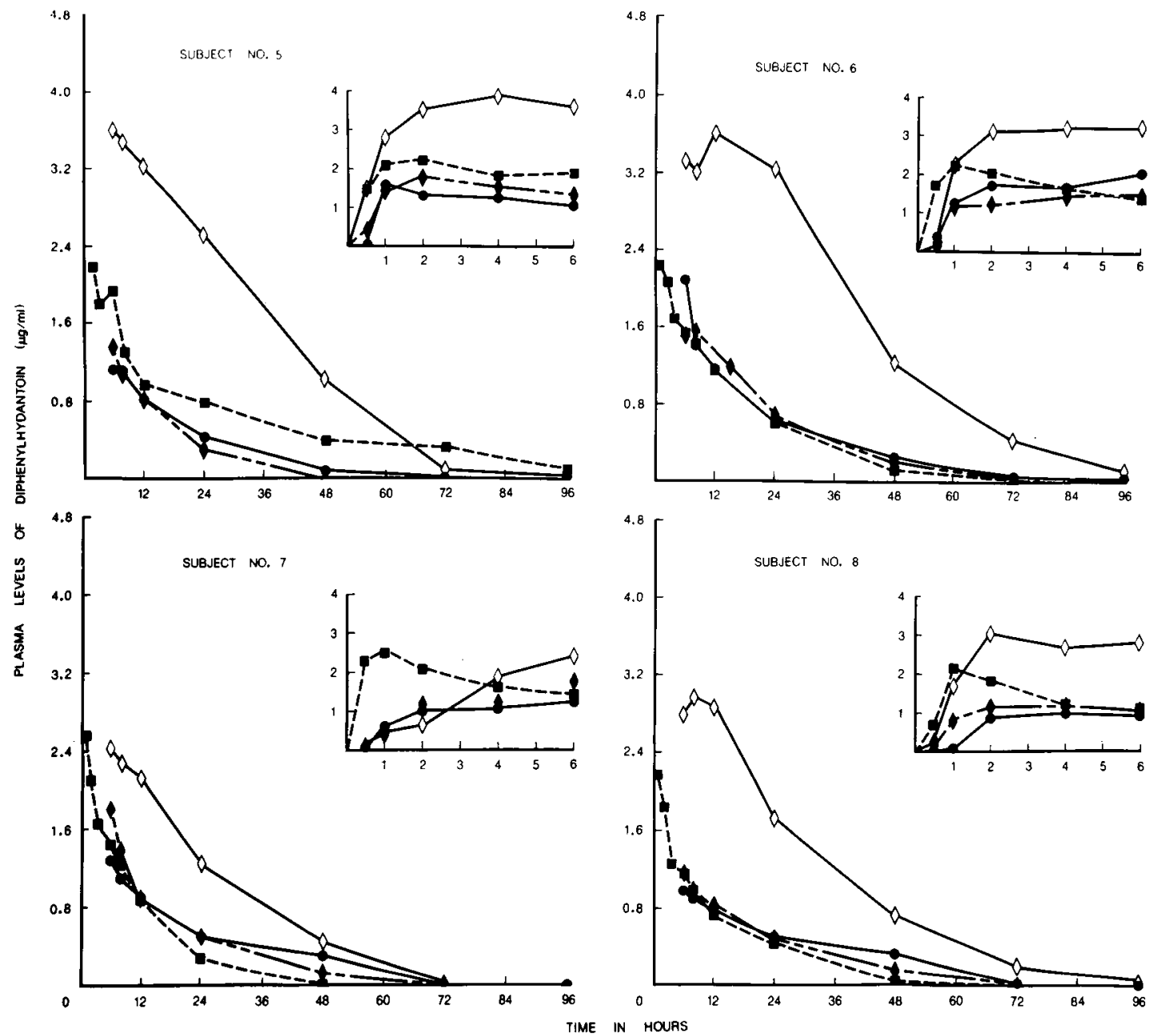

Fig. 2. DPH plasma concentration time data in Subjects 5 to 8 following 4 oral treatments: treatment A from time of peak to $96 \mathrm{hr}$; treatments B, C, and D from $6 \mathrm{hr}$ to $96 \mathrm{hr}$. Inserts show expanded 0 to $6 \mathrm{hr}$ data. See Fig. 1 for further explanation.

administration of drug, suggesting that DPH in solution given orally (treatment A) was more rapidly absorbed than $\mathrm{DPH}$ formulated as the innovator's capsule (treatment B). Tables IV and V support this by showing that the differences between mean times of individual subjects to attain peak concentrations were significant. These results are clearly illustrated in Figs. 1 to 3. On the other hand, since no significant differences in average areas under the plasma curves following treatments A and B occurred, their bioavailabilities were considered to be equivalent. Tables II through $\mathrm{V}$ also show that the generic $100 \mathrm{mg}$ capsule (treatment D) was bioequivalent to the innovator's 100 mg capsule (treatment B) because there were no significant differences between treatment means at any sampling time and average areas under the plasma curves.

Fig. 4 compares average areas ( 0 to 96 hours) following the 4 treatments. The lines at the top of the bars mark off plus and minus one standard deviation of the mean in each case. It is apparent from the figure and the data in Table IV that the area following administration of three 100 mg capsules (treatment $\mathrm{C}$ ) was three times 
the area following administration of a single $100 \mathrm{mg}$ capsule (treatment B).

Other sources of variation. No significant differences were observed among time periods following the four treatments. However, significant differences $(\mathrm{p} \leq 0.05)$ were found between groups 1 and 4 at 6 , 8,12 , and 24 hours post administration of drug and in areas under the plasma concentration time curves. This suggested that the plasma DPH differences could be related to the reciprocal of body weight as would be expected if the volume of distribution of DPH was directly proportional to body weight.

The regression equation for a plot of area against $\mathrm{mg} / \mathrm{kg}$ dose is: $\mathrm{y}=37.2 \mathrm{x}-$ 0.544 with $\mathrm{r}=0.824$. The intercept did not differ significantly from zero. If Subject 1 was not included in the linear regression, then $75 \%$ of the variance in area among subjects could be accounted for in terms of $\mathrm{mg} / \mathrm{kg}$ dose.

Plasma protein binding. Table VI shows the per cent unbound DPH for each subject at two concentrations. Since the fraction unbound appeared to be independent of concentration in the range of plasma drug levels observed in this study, a direct comparison of total plasma concentrations to assess bioavailability was justified. The values in Table VI compare favorably with those reported previously. ${ }^{12}$

\section{Discussion}

Influence of physicochemical factors. The effects of dosage from variables on therapeutic efficacy or bioavailability will be manifest principally in differences in rate of absorption or differences in efficiency of absorption. Significant differences were shown in time of peak and peak plasma concentration of DPH following treatments $A$ and $B$, indicating that DPH in solution given orally was more rapidly absorbed than drug formulated as the innovator's capsule. On the other hand, since no significant differences were shown in areas following the two treatments, the drug in capsule form was fully available relative
Table II. Average DPH plasma concentrations and their corresponding coefficients of variation in per cent for the 8 normal subjects

\begin{tabular}{cccccc}
\hline \multirow{4}{*}{$\begin{array}{c}\text { Time } \\
(\mathrm{hr})\end{array}$} & \multicolumn{4}{|c}{$\begin{array}{c}\text { Mean plasma levels }(\mu \mathrm{g} / \mathrm{ml} \text { ) and } \\
\text { coefficients of variation }(\%)\end{array}$} \\
\cline { 2 - 5 } & Treat- & Treat- & Treat- & Treat- \\
ment A & ment B & ment C & ment $D$ \\
\hline 0.5 & 1.58 & 0.18 & 0.37 & 0.31 \\
& $(38.4)$ & $(116)$ & $(121)$ & $(80.3)$ \\
1 & 2.33 & 0.74 & 1.35 & 1.03 \\
& $(17.1)$ & $(67.4)$ & $(69.6)$ & $(41.6)$ \\
2 & 2.18 & 1.07 & 2.60 & 1.46 \\
& $(17.2)$ & $(37.7)$ & $(44.2)$ & $(25.6)$ \\
4 & 1.87 & 1.25 & 3.03 & 1.66 \\
& $(26.6)$ & $(27.4)$ & $(26.1)$ & $(17.5)$ \\
6 & 1.65 & 1.32 & 3.27 & 1.62 \\
& $(22.7)$ & $(28.1)$ & $(23.5)$ & $(19.7)$ \\
8 & 1.45 & 1.23 & 3.32 & 1.44 \\
& $(27.9)$ & $(24.3)$ & $(28.1)$ & $(19.1)$ \\
12 & 1.13 & 1.20 & 3.17 & 1.17 \\
& $(30.8)$ & $(42.3)$ & $(24.9)$ & $(28.2)$ \\
24 & 0.64 & 0.73 & 2.47 & 0.65 \\
& $(41.0)$ & $(55.8)$ & $(37.1)$ & $(33.1)$ \\
48 & 0.21 & 0.38 & 1.06 & 0.20 \\
& $(81.0)$ & $(109)$ & $(51.4)$ & $(82.4)$ \\
72 & 0.13 & 0.14 & 0.31 & 0.06 \\
& $(112)$ & $(148)$ & $(80.7)$ & $(125)$ \\
96 & 0.05 & 0.05 & 0.10 & 0.01 \\
& $(150)$ & $(102)$ & $(138)$ & $(175)$ \\
\hline
\end{tabular}

- Bracketed values are coefficients of variation of the means, in per cent, i.e. (standard deviation $/$ mean) $\times 100$.

to the drug in solution. From a therapeutic point of view, the complete availability of DPH from the innovator's capsule is noteworthy because the drug is given several times a day for prolonged periods. Rapid absorption is probably less important, and, in fact, may be undesirable because of side effects due to either high initial blood levels of DPH or adverse reaction to the vehicle itself. Nausea and diarrhea were two common side effects following administration of drug in solution that were absent following the three other treatments.

The innovator's $100 \mathrm{mg}$ capsule (treatment B) and the generic $100 \mathrm{mg}$ capsule (treatment D) were found to be bioequivalent, indicating that formulation differences had no effect on bioavailability for the two products tested. Similar results were reported by Glazko, ${ }^{7}$ who found 


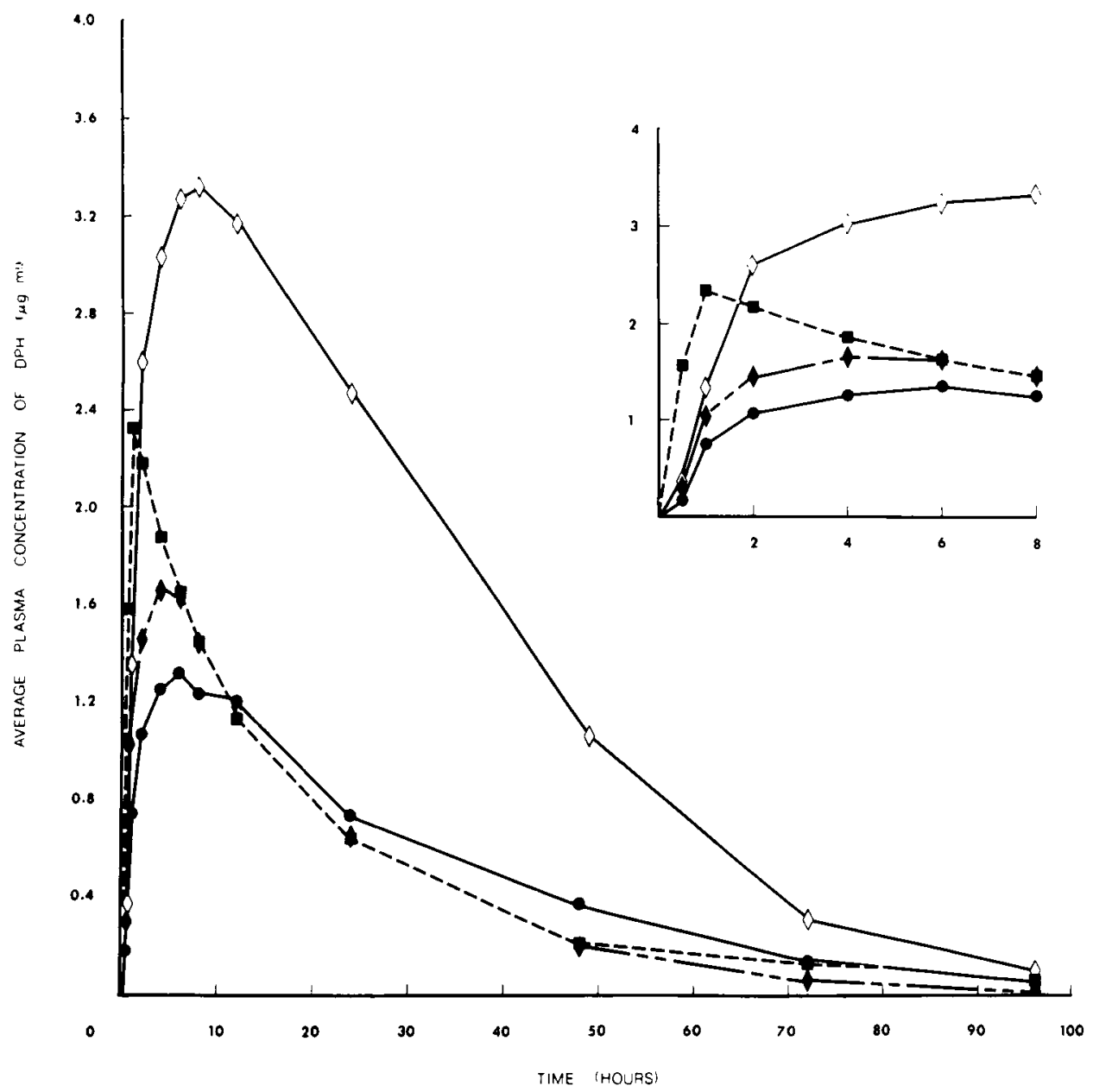

Fig. 3. Average DPH plasma levels for 8 subjects following 4 oral treatments. Insert shows expanded 0 to $6 \mathrm{hr}$ data. See Fig. 1 for further explanation.

Table III. Results of analyses of variance and multiple-range tests for comparison of average plasma levels of diphenylhydantoin

\begin{tabular}{c|c|c|c|c}
\hline & & \multicolumn{3}{|c}{ Significance level } \\
\cline { 2 - 5 } Time (hr) & C.V. (\%) & $\begin{array}{c}\text { Among treatments } A, B, C, \\
\text { and } D\end{array}$ & $\begin{array}{c}\text { Between treatments } \\
A \text { and } B\end{array}$ & $\begin{array}{c}\text { Between treatments } \\
B \text { and } D\end{array}$ \\
\hline 0.5 & 63.2 & $\mathrm{p}<0.001$ & $\mathrm{p} \leq 0.05$ & N.S.† \\
1 & 42.0 & $\mathrm{p}<0.001$ & $\mathrm{p} \leq 0.05$ & N.S. \\
2 & 38.1 & $0.001<\mathrm{p}<0.005$ & $\mathrm{p} \leq 0.05$ & N.S. \\
4 & 22.7 & $\mathrm{p}<0.001$ & $\mathrm{p} \leq 0.05$ & N.S. \\
6 & 17.4 & $\mathrm{p}<0.001$ & N.S. & N.S. \\
8 & 21.3 & $\mathrm{p}<0.001$ & N.S. & N.S. \\
12 & 19.8 & $\mathrm{p}<0.001$ & N.S. & N.S. \\
24 & 35.4 & $\mathrm{p}<0.001$ & N.S. & N.S. \\
48 & 61.5 & $\mathrm{p}<0.001$ & N.S. & N.S. \\
72 & 79.9 & $0.001<\mathrm{p}<0.005$ & N.S. & N.S. \\
96 & 123 & N.S. & N.S. & N.S. \\
\hline
\end{tabular}

${ }^{\circ}$ Coefficient of variation, in per cent, from the residual mean square of the analysis of variance.

†Not significant.

\$ Borderline level of significance. 
Table IV. Pharmacokinetic parameters derived from DPH plasma concentration, time data, and their corresponding coefficients of variation

\begin{tabular}{|c|c|c|c|c|}
\hline \multirow[b]{2}{*}{ Parameter } & \multicolumn{4}{|c|}{ Parameter value and coefficient of variation (\%) } \\
\hline & Treatment $A$ & Treatment $B$ & Treatment $C$ & Treatment $D$ \\
\hline Peak plasma concentration $(\mu \mathrm{g} / \mathrm{ml})$ & $\begin{array}{c}2.42 \\
(14.3)^{\circ}\end{array}$ & $\begin{array}{c}1.48 \\
(29.3)\end{array}$ & $\begin{array}{c}3.52 \\
(25.4)\end{array}$ & $\begin{array}{c}1.80 \\
(15.0)\end{array}$ \\
\hline Time of peak (hr) & $\begin{array}{r}1.63 \\
(65.3)\end{array}$ & $\begin{array}{c}6.63 \\
(63.0)\end{array}$ & $\begin{array}{c}6.00 \\
(56.3)\end{array}$ & $\begin{array}{r}4.50 \\
(46.0)\end{array}$ \\
\hline Area $0 \rightarrow 96 \mathrm{hr}(\mu \mathrm{g} / \mathrm{ml} \times \mathrm{hr})$ & $\begin{array}{c}46.5 \\
(38.3)\end{array}$ & $\begin{array}{l}47.0 \\
(58.3)\end{array}$ & $\begin{array}{c}132 \\
(36.8)\end{array}$ & $\begin{array}{l}41.3 \\
(32.3)\end{array}$ \\
\hline Area $0 \rightarrow \infty(\mu \mathrm{g} / \mathrm{ml} \times \mathrm{hr})$ & $\begin{array}{c}49.1 \\
(40.8)\end{array}$ & $\begin{array}{c}49.2 \\
(57.5)\end{array}$ & $\begin{array}{c}134 \\
(38.5)\end{array}$ & $\begin{array}{c}41.8 \\
(32.6)\end{array}$ \\
\hline
\end{tabular}

*Bracketed values are coefficients of variation of the means, in per cent, i.e. (standard deviation/mean) $\times 100$.

Table V. Results of analyses of variance and multiple-range tests for comparison of pharmacokinetic parameters derived from DPH plasma levels

\begin{tabular}{l|c|c|c|c}
\hline & & \multicolumn{3}{|c}{ Significance level } \\
\cline { 2 - 5 } \multicolumn{1}{c|}{ Parameter } & C.V. $(\%)^{*}$ & $\begin{array}{c}\text { Among treatments } \\
A, B, C, \text { and } D\end{array}$ & $\begin{array}{c}\text { Between treatments } \\
A \text { and } B\end{array}$ & $\begin{array}{c}\text { Between treatments } \\
B \text { and } D\end{array}$ \\
\hline Peak plasma level & 21.3 & $\mathrm{p}<0.001$ & $\mathrm{p} \leq 0.05$ & N.S.f \\
Time of peak & 50.5 & $0.001<\mathrm{p}<0.005$ & $\mathrm{p} \leq 0.05$ & N.S. \\
Area $0 \rightarrow \infty$ & 32.0 & $\mathrm{p}<0.001$ & N.S. & N.S. \\
Area $0 \rightarrow 96 \mathrm{hr}$ & 33.8 & $\mathrm{p}<0.001$ & N.S. & N.S. \\
\hline
\end{tabular}

${ }^{\circ}$ Coefficient of variation in per cent from the residual mean square of the analysis of variance.

$\nmid$ Not significant.

Table VI. Plasma protein binding of DPH using subject plasma from treatment $C$

\begin{tabular}{|c|c|c|c|c|}
\hline Subject & $W t(\mathrm{~kg})$ & $D P H(\mu \mathrm{g} / \mathrm{ml})$ & \% unbound & Subject average \\
\hline 1 & 70.5 & $\begin{array}{l}0.0488(12 \mathrm{hr}) \\
3.57(12\end{array}$ & $\begin{array}{l}5.7 \\
5.7\end{array}$ & 5.7 \\
\hline 2 & 71.8 & $\begin{array}{l}0.0488 \\
3.47(8 \mathrm{hr})\end{array}$ & $\begin{array}{l}8.8 \\
7.9\end{array}$ & 8.4 \\
\hline 3 & 72.3 & $\begin{array}{l}0.0488 \\
4.58(8 \mathrm{hr})\end{array}$ & $\begin{array}{l}7.6 \\
7.3\end{array}$ & 7.5 \\
\hline 4 & 76.8 & $\begin{array}{l}0.0488 \\
2.19(2 \mathrm{hr})\end{array}$ & $\begin{array}{l}5.9 \\
5.1\end{array}$ & 5.5 \\
\hline 5 & 79.1 & $\begin{array}{l}0.0488 \\
3.23(12 \mathrm{hr})\end{array}$ & $\begin{array}{l}6.6 \\
6.5\end{array}$ & 6.6 \\
\hline 6 & 81.8 & $\begin{array}{l}0.0488 \\
3.23(8 \mathrm{hr})\end{array}$ & $\begin{array}{l}6.4 \\
6.9\end{array}$ & 6.7 \\
\hline 7 & 81.8 & $\begin{array}{l}0.0488 \\
2.28(8 \mathrm{hr})\end{array}$ & $\begin{array}{l}7.2 \\
8.7\end{array}$ & 7.9 \\
\hline 8 & 95.5 & $\begin{array}{l}0.0488 \\
2.99(8 \mathrm{hr})\end{array}$ & $\begin{array}{l}6.0 \\
6.5\end{array}$ & 6.3 \\
\hline $\begin{array}{l}\text { Mean } \\
\text { S.D. }\end{array}$ & & & $\begin{array}{l}6.8 \\
1.1\end{array}$ & \\
\hline
\end{tabular}

that DPH capsules from four different manufacturers gave plasma levels that were not significantly different. However, bioequivalence needs to be demonstrated for each manufacturer's formulation. The results reported herein do not imply that other DPH capsules, made by the same or different manufacturers, will provide satisfactory results in man. DPH following treatments $\mathrm{B}$ and $\mathrm{D}$ also appeared to be released from their respective capsules nonuniformly as evidenced by the non- 


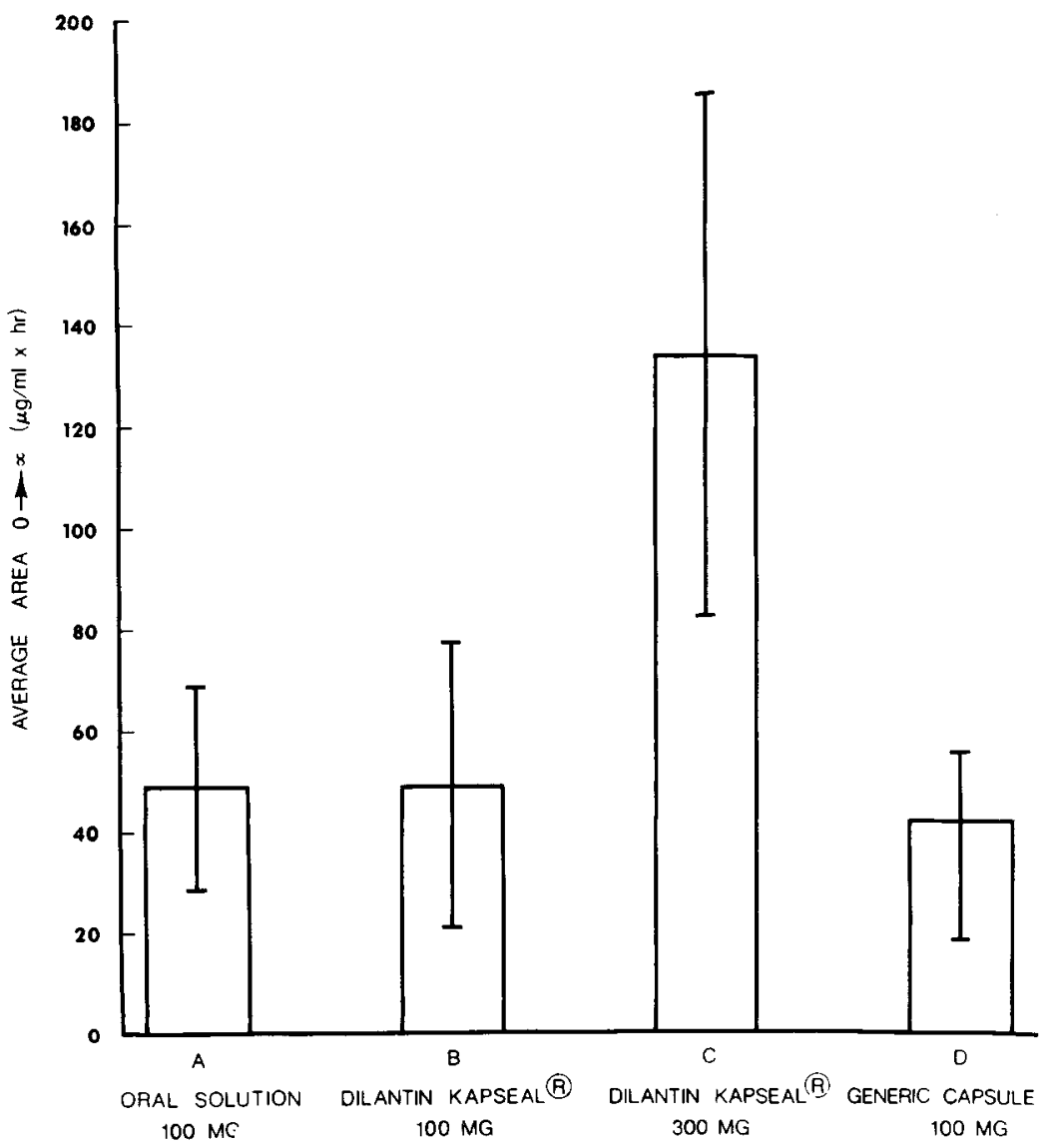

Fig. 4. Comparison of average areas under DPH plasma concentration time curves for 8 subjects given 4 different treatments. The lines mark off \pm .1 standard deviation of the mean in each case.

continuous appearance of the individual plasma curves (inserts of Figs. 1 and 2) from zero time to 6 hours postadministration of drug. This effect, which was absent for the corresponding time interval following administration of DPH in solution (except for Subject 5), has not been reported formerly.

Influence of physiological and biochemical factors. Figs. 1 to 3 reveal evidence for three distinct factors that may influence the absorption, distribution, and elimination of DPH in man. These factors are (1) lag time for absorption, (2) bile cycling, and (3) saturation kinetics.

The individual plasma curves (inserts of Figs. 1 and 2) suggest a lag time for absorption of DPH following treatments B, $\mathrm{C}$, and D. This may be due to dissolution of the drug from the capsule and gastric emptying since DPH is mainly absorbed from the intestinal tract.

Evidence for enterohepatic (bile) cycling is provided by what appears to be an additional absorptive component in the plasma curve during distribution or elimination. The effect is particularly pronounced in Subjects 1, 3, and 6. Although bile cycling of DPH may be implicated in the metabolic disposition of the drug, ${ }^{7,8}$ inference of its existence from our data is speculative.

The nonlinear elimination characteristics of DPH are exemplified in Figs. 1, 2, and 3 by the characteristic "hockey-stick" shape of the plasma curves following treatment C (300 mg dose). Large errors in bioavailability estimates can sometimes be 
made for drugs such as DPH, which exhibit saturation-kinetics because the dose/ area ratio is dose-dependent (i.e., plasma clearance is not constant). However, this study clearly shows a linear relationship between area and dose of DPH in the therapeutic range of 100 to $300 \mathrm{mg}$ (Fig. 4). Similar results have been reported by $\mathrm{Glazko}^{7}$ in the 200 to $400 \mathrm{mg}$ range.

Influence of plasma protein binding. Jähnchen and Levy ${ }^{11}$ have suggested that the intersubject variability associated with many pharmacokinetic parameters may be related to intersubject differences in plasma protein binding. This hypothesis with $\mathrm{DPH}$ in man was tested by plotting area against $(D / W)(1 / \sigma)$ where $D / W$ is the $\mathrm{mg} / \mathrm{kg}$ dose and $\sigma$ is the fraction of drug unbound. When the correlation coefficient was compared against that for area against $\mathrm{D} / \mathrm{W}$, there was no improvement $(0.80$ and 0.82 ). Hence, plasma protein binding probably exerted little if any influence on the intersubject variability observed in the areas.

Pharmacokinetic implications. Previous investigations by others ${ }^{7,8,10,17}$ and this report suggest that $\mathrm{DPH}$ is susceptible to enterohepatic cycling. In addition, there appears to be a lag time and nonuniform input kinetics when capsules are administered. Hence, elaboration of a pharmacokinetic model, which ignores these considerations, may be tenuous.

\section{References}

1. Arnold, K., and Gerber, N.: The rate of decline of diphenylhydantoin in human plasma, Clin. Pharmacol. Ther. 11:121-134, 1970.

2. Arnold, K., Gerber, N., and Levy, G.: Absorption and dissolution studies on sodium diphenylhydantoin capsules, Canad. J. Pharm. Sci. 5:89-92, 1970.

3. Dill, W. A., Chucot, L., Chang, T., and Glazko, A. J.: Simplified benzophenone procedure for determination of diphenylhydantoin in plasma, Clin. Chem. 17:1200-1201, 1971.

4. Di Palma, J. R., editor: Drill's Pharmacology in medicine, ed. 4, New York, 1971, McGrawHill Book Company.

5. Dixon, W. J., and Massey, F. J., Jr.: Introduction to statistical analysis, New York, 1957,
McGraw-Hill Book Company, Inc., chap. 10. 6. Gerber, N., and Wagner, J. G.: Explanation of dose-dependent decline of diphenylhydantoin plasma levels by fitting to the integrated form of the Michaelis-Menten equation, Res. Commun. Chem. Pathol. Pharmacol. 3:455466, 1972.

7. Glazko, A. J.: Diphenylhydantoin, Pharmacology 8:163-167, 1972.

8. Glazko, A. J., and Chang, T.: Diphenylhydantoin. Absorption, distribution and excretion of antiepileptic drugs, in Woodbury, D. M., Penry, J. K., and Schmidt, R. P., editors: Antiepileptic drugs, New York, 1972, Raven Press, pp. 131-132.

9. Glazko, A. J., Chang, T., Baukema, J., Dill, W. A., Goulet, J. R., and Buchanan, R. A.: Metabolic disposition of diphenylhydantoin in normal human subjects following intravenous administration, Clin. Pharmacol. Ther, 10: 498-504, 1969.

10. Glazko, A. J., Dill, W. A., Drach, J. C., and Chang, T.: Biological availability of drugs. Evaluation from blood level and urinary excretion data, in compilation of symposium papers presented to APhA Academy of Pharmaceutical Sciences, Fifth National Meeting, Washington, D. C., 1968, pp. 326-343.

11. Jähnchen, E., and Levy, G.: Relationship between distribution, elimination and anticoagulant action of dicumarol, J. Pharmacol. Exp. Ther. 188:293-299, 1974.

12. Lunde, P. K. M., Rane, A., Yaffe,-S. J., Lund, L., and Sjöqvist, F.: Plasma protein binding of diphenylhydantoin in man, Clin. Pharmacol. THER. 11:846-855, 1970.

13. Martin, C. M., Rubin, M., O'Malley, W., Garaguai, V. F., and McCauley, C. E.: Comparative physiological availability of "brand" and "generic" drugs in man: Chloramphenicol, sulfisoxazole and diphenylhydantoin, Pharmacologist 10:167, 1968.

14. Saitoh, Y., Nishihara, K., Nakagawa, F., Suzuki, T.: Improved microdetermination for diphenylhydantoin in blood by U.V. spectrophotometry, J. Pharm. Sci. 62:206-210, 1973.

15. Steel, R. G. D., and Torrie, J. H.: Principles and procedures of statistics, New York, 1960, McGraw-Hill Book Company, Inc., pp. 107110.

16. Woodbury, D. M., Penry, J. K., and Schmidt, R. P., editors: Antiepileptic drugs, New York, 1972, Raven Press, chap. 18 and 19.

17. Woodbury, D. M., and Swinyard, E. A.: Diphenylhydantoin. Absorption, distribution, and excretion of antiepileptic drugs, in Woodbury, D. M., Penry, J. K., and Schmidt, R. P., editors: Antiepileptic drugs, New York, 1972, Raven Press, pp. 119-120. 